TAO, Vol. 17, No. 1, 129-138, March 2006

\title{
Rescaled Range Analysis of Microtremors in the Yun-Chia Area, Taiwan
}

\author{
Young-Fo Chang ${ }^{1, *}$, Chien-Chih Chen ${ }^{2}$, and Huey-Chu Huang ${ }^{1}$
}

(Manuscript received 26 March 2004, in final form 13 September 2005)

\begin{abstract}
Hurst's analysis of natural background microtremors at 10 stations in Yun-Li and Chia-Yi Counties, Taiwan, yields high values of $H$, ranging from 0.733 to 0.934 . These values are found to be site-specific and stationary. Microtremors recorded in the foothills, on a hillside and at rock sites have higher $H$ values than those on the alluvial plain, near the coast or at soil sites although they may very well be affected by the local environment and geology. Since low-frequency microtremors tend to be more persistent in time, we suggest that the high values of the Hurst exponent $H$ may be causally correlated with the presence of low frequencies. This seems likely because Hurst exponents $\boldsymbol{H}>0.5$ mean a higher statistical persistence of a random signal.
\end{abstract}

(Key words: Rescaled range, Microtremor, Memory effect, Fractal dimension)

\section{INTRODUCTION}

Microtremors are the sum (or mixture) of different types of ground motion and therefore cannot be identified as being directly associated with any particular event of finite duration, such as earthquakes or explosions. Most commonly, they are simply classified as noise. While the sources and typical frequency band of microtremors do change from place to place, they are also time-dependent. Microtremors generated from either sea waves or coast surf, for example, have relatively lower frequency components, but those caused by traffic and industrial activity in urban areas are dominated by signals with frequencies higher than $1 \mathrm{~Hz}$ (Seht and Wohlenberg 1999).

\footnotetext{
${ }^{1}$ Institute of Seismology, National Chung-Cheng University, Chia-Yi, Taiwan, ROC

2 Institute of Geophysics, National Central University, Chung-Li , Taiwan, ROC

* Corresponding author address: Prof. Young-Fo Chang, Institute of Seismology, National ChungCheng University, Chia-Yi, Taiwan, ROC; E-mail: seichyo@eq.ccu.edu.tw
} 
More than half a century ago, Hurst (1951) first proposed an empirical relationship to describe the long-term characteristics of the discharge from the River Nile. Since then, his methodology has come to be known as 'the rescaled range technique'. Almost two decades later, Mandelbrot and Wallis (1969a, b) demonstrated that a large number of geophysical records were highly consistent with Hurst's empirical relationship. Feder (1988) later publicized and solidified the method even further. And ever since, this technique has proven its efficiency in the study of the statistical characteristics of data for many natural phenomena with fractals (Mandelbrot 1983; Feder 1988). Furthermore, Lomnitz (1994) adopted this technique to estimate seismic energy distributed over time for the study of risk assessment, and Komm (1995) applied the technique to study temporal variations in solar rotation and concluded that such variations in solar rotation are as persistent for time scales as short as about 20 days and for those as long as a few thousand years. Urquizu and Correig (1998) also used it to calculate the Hurst exponents of S-coda waves, commonly referred to as $H$ values, and the $H$ values of the microtremors recorded in the eastern Pyrenees. They found that the $H$ value of these is respectively 0.85 and 0.82 . More recently, Macchiato (2001) has shown that changes in the $H$ values of seismicity in southern Italy are highly correlated with major seismic events.

Lomnitz (1994) proposed that when the rescaled range technique is used for risk assessment, such appropriate additive variables as seismic moment and energy must be very carefully selected. To estimate the $H$ values, the same dataset may exhibit both persistent and antipersistent properties whether they are suitably differentiated or integrated (Karner 2001). Although it has been 50 years since Hurst first proposed the rescaled range technique, the technique still remains an open problem in stochastic geophysical signals.

In earthquake engineering, microtremors are usually employed to investigate site effects (Ohta et al. 1978; Kagami et al. 1982; Lermo and Chavez-Garcia 1994), but the methods of analysis generally assume that microtremors are stationary in time and that the time duration of the microtremors chosen for analysis is typically less than 30 minutes. Similarly, Urquizu and Correig (1998) claimed that their 30-minute microtremors recorded at Cadi station in the eastern Pyrenees were stationary. However, the amplitudes and frequency contents of microtremors may vary in different recording periods (Okada 2003). Whether or not the longterm characteristics, or $H$ values, of microtremors are stationary is important here.

In this study, we applied Hurst's rescale range technique to analyze microtremors in the Yun-Chia area, Taiwan, first to examine whether or not they are uncorrelated independent random noise and, secondly, to determine the implications of the distribution of the $H$ values in this area.

\section{HURST'S RESCALED RANGE TECHNIQUE}

We provide a brief but concise summary of Hurst's rescaled range method below; however, further details about the technique can be widely found in the published literature (e.g., Feder 1988).

The range $(R)$ is the difference between the maximum and minimum amounts of the accumulated departures of a time series. The standard deviation of a time series is denoted by 
S. Hurst (1951) found that the observed rescaled range $(R / S)$ for many records in time is very well defined by the following empirical relation:

$$
R / S=(\tau / 2)^{H},
$$

where $H$ is the Hurst exponent, and $\tau$ is the time-span considered in the calculation. $H$ describes the correlation between the past and future in the time series. For independent random processes with finite variances, the $H$ value is 0.5 . When $H>0.5$, the time series is persistent, which means that an increasing trend in the past is indicative of an increasing trend in the future. Conversely, as a general rule, a decreasing trend in the past signifies a persistent decrease in the future. When $H<0.5$, the time series is anti-persistent, which means that an increasing trend in the past implies a decreasing trend in the future and vice-versa (Feder 1988). Mandelbrot and Wallis (1969a, b) used this technique to analyze a large number of geophysical records and determined that their $H$ values were mostly greater than 0.5 . If the time series is self-similar and self-affine, then its fractal dimension $(D)$ can be expressed as $D=2-H$ (Mandelbrot 1983; Feder 1988).

\section{DATA AND RESULTS}

To understand the long-term statistical characteristics of microtremors, we measured microtremors at 10 different stations distributed in Yun-Lin and Chia-Yi Counties in Taiwan (Fig. 1). We used a hand-type seismocorder system (SPC-51) with a three-component velocity sensor (VSE-15D). The sensitivity range was between 0.1 and $70 \mathrm{~Hz}$. The sampling rate was $200 \mathrm{~Hz}$ on a permanent 16-bit, 16-channel data acquisition system. We continuously recorded the microtremors at each station for 18 or 28 minutes. Stations C008, C027, C031, C044, C055, C104 and C106 (Fig. 1) are located on the Western alluvial plain of Taiwan, but among these, stations C027 and C044 are close to the sea, and C104 and C106 are on a hillside. Three other stations C006, C028 and C074 are located on the Western foothills, but C074 is located on Ali-Shan Mountain. The background noise at all of the locations is very small. In order to test whether the microtremors are stationary in time, we re-measured the microtremors at 5 stations (C006, C008, C028, C031 and C055) for an additional 18 minutes in a different recording period.

Figures 2 and 3 present the waveforms of the NS-component of the microtremors recorded at stations C008 (a soil site) and C028 (a rock site). Figures 2a and b as well as 3a and $\mathrm{b}$ show the microtremors measured at the same station but in different recording periods. In Figs. 2a and 3a, the top panel shows the waveform for 0- to 60-second microtremors; the waveform in the middle and the one at the bottom are $0-10$ and $0-1$ seconds, respectively. The same pattern is shown in Figs. $2 \mathrm{~b}$ and $3 \mathrm{~b}$. In these figures, we can predict neither the direction nor the magnitude of ground motion at any of the sampling times. Both visually and intuitively, the microtremors are random. When Figs. 2a and 3a are compared with Figs. 2b and $3 b$, it is very apparent that the amplitudes and frequency contents of the microtremors recorded during different recording periods are different. Thus, we conclude that microtremors 


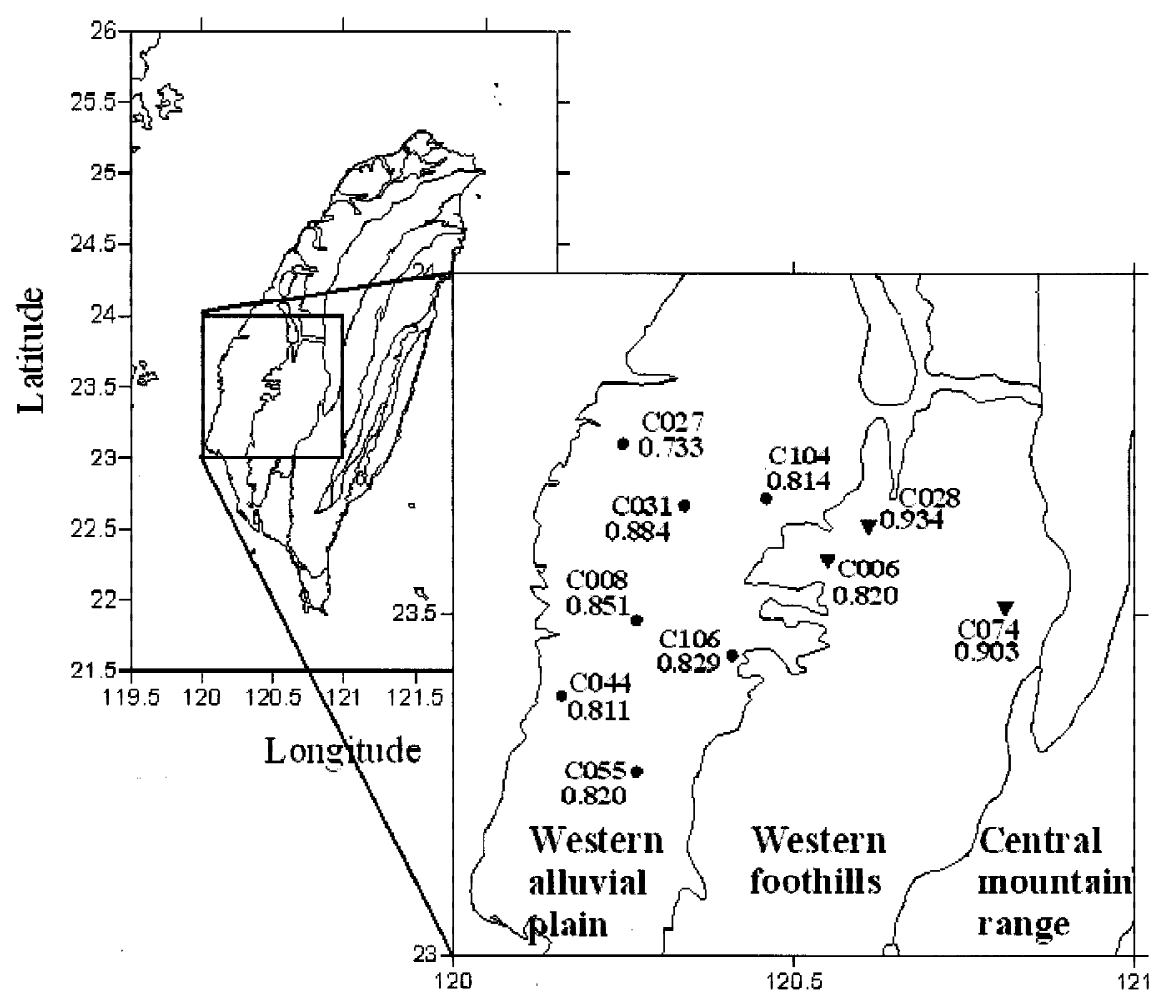

Fig. 1. Locations of the 10 stations used for the microtremor measurements in the Yun-Chia area, Taiwan. C008, C027, C031, C044, C055, C104 and C106 (black dots) are located on the Western alluvial plain, and the C006, C028 and C074 (black triangles) are located in the Western foothills. The $H$ value of the microtremors is given below the name code of each station.

are nonstationary in time. In the 0 - to 10 -second waveforms, the low-frequency $(0.25-1 \mathrm{~Hz})$ ground motion has a larger amplitude than does the high-frequency ground motion. This finding indicates that the microtremors have high $H$ values (Feder 1988). For simplification, in this study, we considered only the scalar amplitude of the microtremors. For the 18- and 28minute microtremor records, the $\tau$ values are respectively $0.005-1080$ and $0.005-1680$ seconds. However, to save computation time, for the calculation of their respective $R / S$ values and to estimate their $H$ values, we only selected thirty values of $\tau$ which were uniformly distributed on the $\log$ scale. Mandelbrot and Wallis (1969) indicated that small $\tau$ values seem to overestimate $H$ values but that large $\tau$ values seem to underestimate $H$ values. Therefore, we only chose $\tau$ values ranging from 1 to 100 to regress the $H$ values. Table 1 shows the results from this study. The $H$ values of the microtremors recorded in the Yun-Chia area range from 0.733 to 0.934 , and they are persistent. 


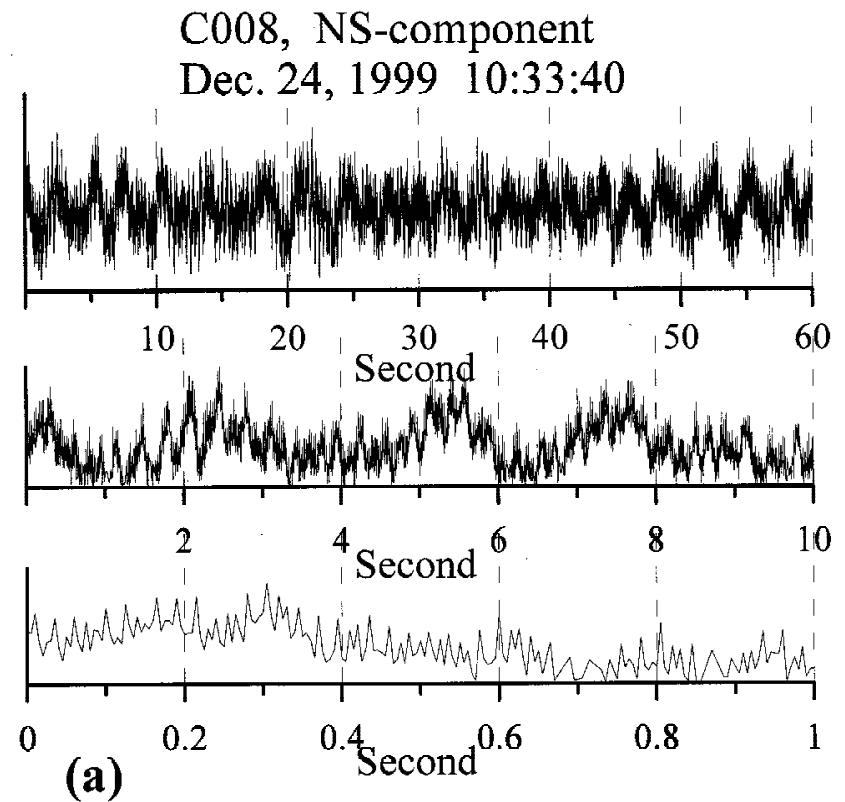

Sep. 18, 2003 11:48:14

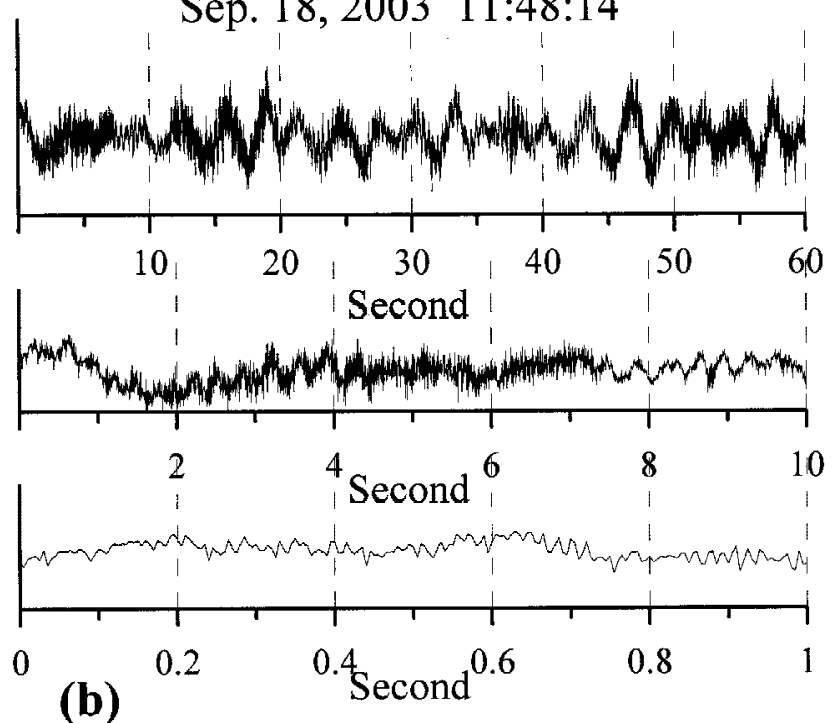

Fig. 2. Sample waveforms of the NS-component of the microtremors recorded at station C008 (a soil site). In the upper waveform, the time window is 0 - 60 seconds. In the middle, it is 0 - 10 seconds, and at the bottom, it is 0 - 1 second. (a) Recorded on Dec. 24, 1999. (b) Recorded on Sep. 18, 2003. 


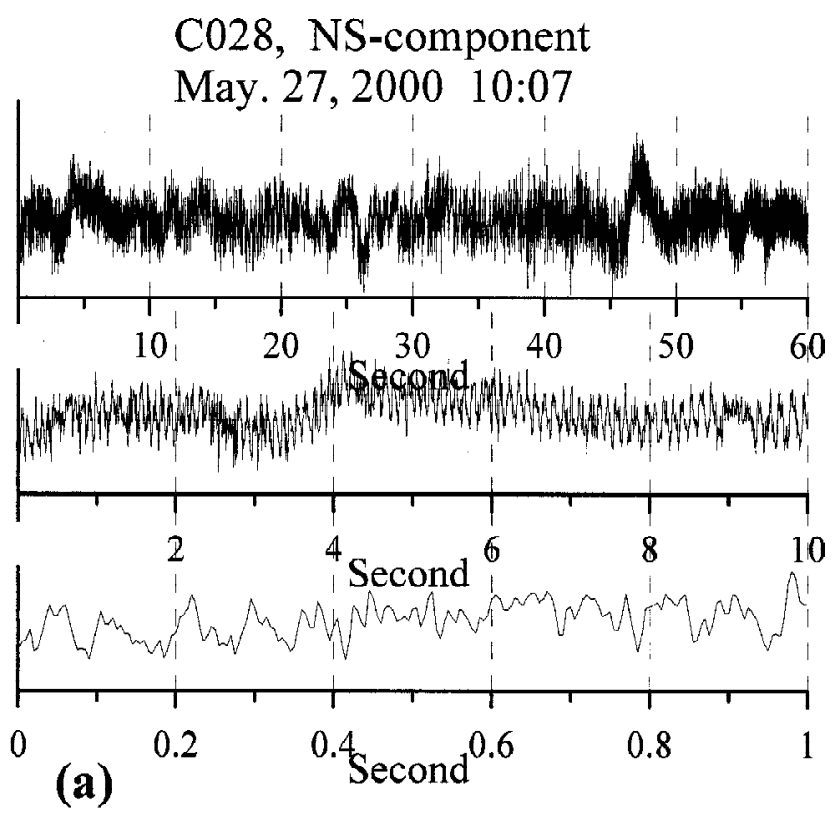

Apr. 05, 2004 16:25
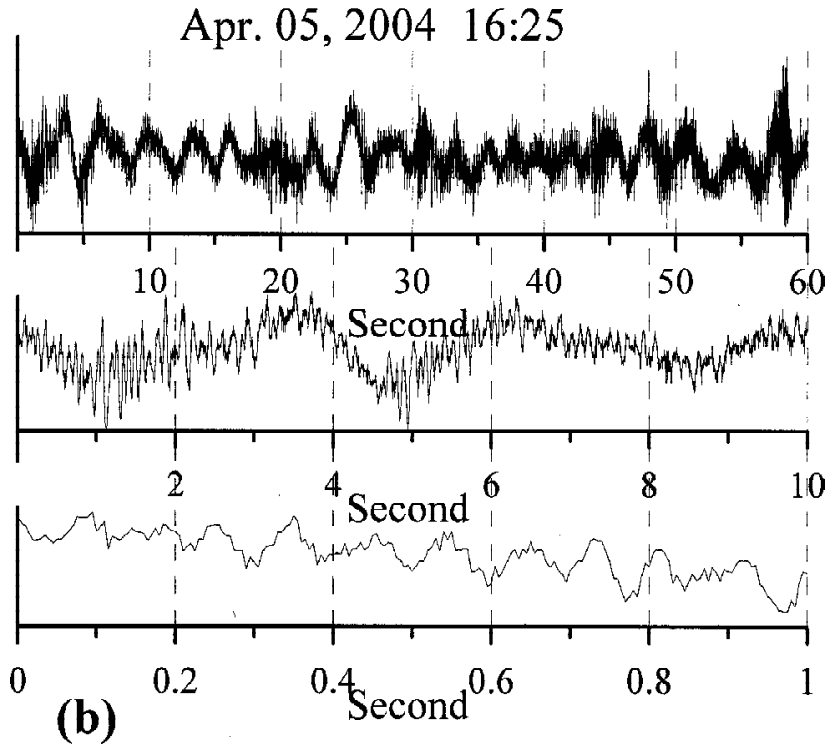

Fig. 3. Sample waveforms of the NS-component of the microtremors recorded at station $\mathrm{C} 028$ (a rock site). In the upper waveform, the time window is 0 - 60 seconds. In the middle, it is $0-10$ seconds, and at the bottom, it is 0 - 1 second. (a) Recorded on May. 27, 2000. (b) Recorded on Apr. 05, 2004. 
Table $1 . H$ values of the microtremors recorded at the 10 stations in the YunChia area, Taiwan.

\begin{tabular}{|c|c|c|c|c|c|c|}
\hline & Data le & gth 18 minutes & Data les & gth 28 minutes & Difference & Average \\
\hline Stations & $\begin{array}{l}H \\
\text { values }\end{array}$ & Recording time & $\begin{array}{l}H \\
\text { values }\end{array}$ & Recording time & $\begin{array}{l}\text { in the } H \\
\text { values, } \Delta H\end{array}$ & $H$ values \\
\hline $\mathrm{C} 006$ & $\begin{array}{l}0.810= \\
0.012\end{array}$ & Apr. 06, 2004, 10:34 & $\begin{array}{l}0.829 \pm \\
0.003\end{array}$ & Mar. 28, 2000, 09:59 & 0.019 & 0.820 \\
\hline $\mathrm{C} 008$ & $\begin{array}{l}0.833 \pm \\
0.007\end{array}$ & Sep. $18,2003,11: 48$ & $\begin{array}{l}0.868 \pm \\
0.024 \\
\end{array}$ & Dec. $24,1999,10: 33$ & 0.035 & 0.851 \\
\hline $\mathrm{C} 027$ & & & $\begin{array}{l}0.733 \pm \\
0.004 \\
\end{array}$ & Dec. $29,1999,13: 41$ & & 0.733 \\
\hline $\mathrm{C} 028$ & $\begin{array}{l}0.925 \pm \\
0.005\end{array}$ & Apr. 05, 2004, 16:25 & $\begin{array}{l}0.942 \pm \\
0.003\end{array}$ & Mar. 27, 2000, 10:07 & 0.017 & 0.934 \\
\hline $\mathrm{C} 031$ & $\begin{array}{l}0.889 \pm \\
0.017 \\
\end{array}$ & Apr. 06, 2004, 17:03 & $\begin{array}{l}0.879 \pm \\
0.007 \\
\end{array}$ & Dec. $29,1999,09: 42$ & -0.010 & 0.884 \\
\hline $\mathrm{C} 044$ & & & $\begin{array}{l}0.811 \pm \\
0.005\end{array}$ & Mar. $20,2000,13: 24$ & & 0.811 \\
\hline $\mathrm{C} 055$ & $\begin{array}{l}0.822 \pm \\
0.018 \\
\end{array}$ & Apr. 07, 2004, 16:39 & $\begin{array}{l}0.817 \pm \\
0.011 \\
\end{array}$ & Jan. $15,2000,12: 33$ & -0.005 & 0.820 \\
\hline $\mathrm{C} 074$ & & & $\begin{array}{l}0.903 \pm \\
0.011\end{array}$ & Mar. 30, 2000, 14:23 & & 0.903 \\
\hline C104 & & & $\begin{array}{l}0.814 \pm \\
0.012\end{array}$ & Mar. 22, 2000, 09:29 & & 0.814 \\
\hline $\mathrm{C} 106$ & $\begin{array}{l}0.829 \pm \\
0.013\end{array}$ & Apr, 05, 2004, 16:24 & & & & 0.829 \\
\hline
\end{tabular}

\section{DISCUSSIONS}

Regardless of whether our 18- and 28-minute microtremor records are long-term, the longest period of sensitivity of the sensor we used in this study was 10 seconds. Therefore, our 18- and 28-minute microtremor records which are far greater than 10 seconds could be treated as long-term records. This enabled us to use this technique to analyze the long-term characteristics of microtremors. The $H$ values of the geophysical data obtained by Mandelbrot and Wallis (1969a) were always greater than 0.5 and had an average $H$ value of about 7.1, though they are scattered. The average $H$ value in this study is 0.84 . Although a high $H$ value is not anomalous or special, it may be related to the origin of the microtremors. If we follow Feder's (1988) high $H$ value theory, whereby low-frequency signals have larger amplitudes than highfrequency signals, then the reason for the high $H$ values of the microtremors here may very well be that it is considerably easier for low frequency ground motions than high frequency ground motions to survive.

The differences in the $H$ values ( $\Delta H$ ) of the microtremors recorded at the same station but in different recording periods range from 0.005 to 0.035 (Table 1); these are $0.6 \%$ to $4 \%$ of 
their $H$ values. The average $H$ value of the microtremors at stations where we took the measurements twice is 0.862 , and the average difference in the $H$ values is 0.05 , or about $6 \%$ of the average $H$ value. Thus, the $H$ values can be thought of as the same in the two measurements. Therefore, the $H$ values (the long-term characteristics) of the microtremors are stationary in time.

The distribution of the $H$ values in the Yun-Chia area along with the elevations of the stations is shown in Fig. 4; the dashed line represents the best exponential fit of the data. Although the data are scattered, the rough trend in the distribution of the $H$ values that emerges is still easily observed. The $H$ values of the microtremors on the alluvial plain, near the coast or at soil sites are lower than those in the foothills, near the mountain or at rock sites although they could be very well affected by the local environment and geology. These results imply that the strength of the long-term statistical dependence of the microtremors recorded in the

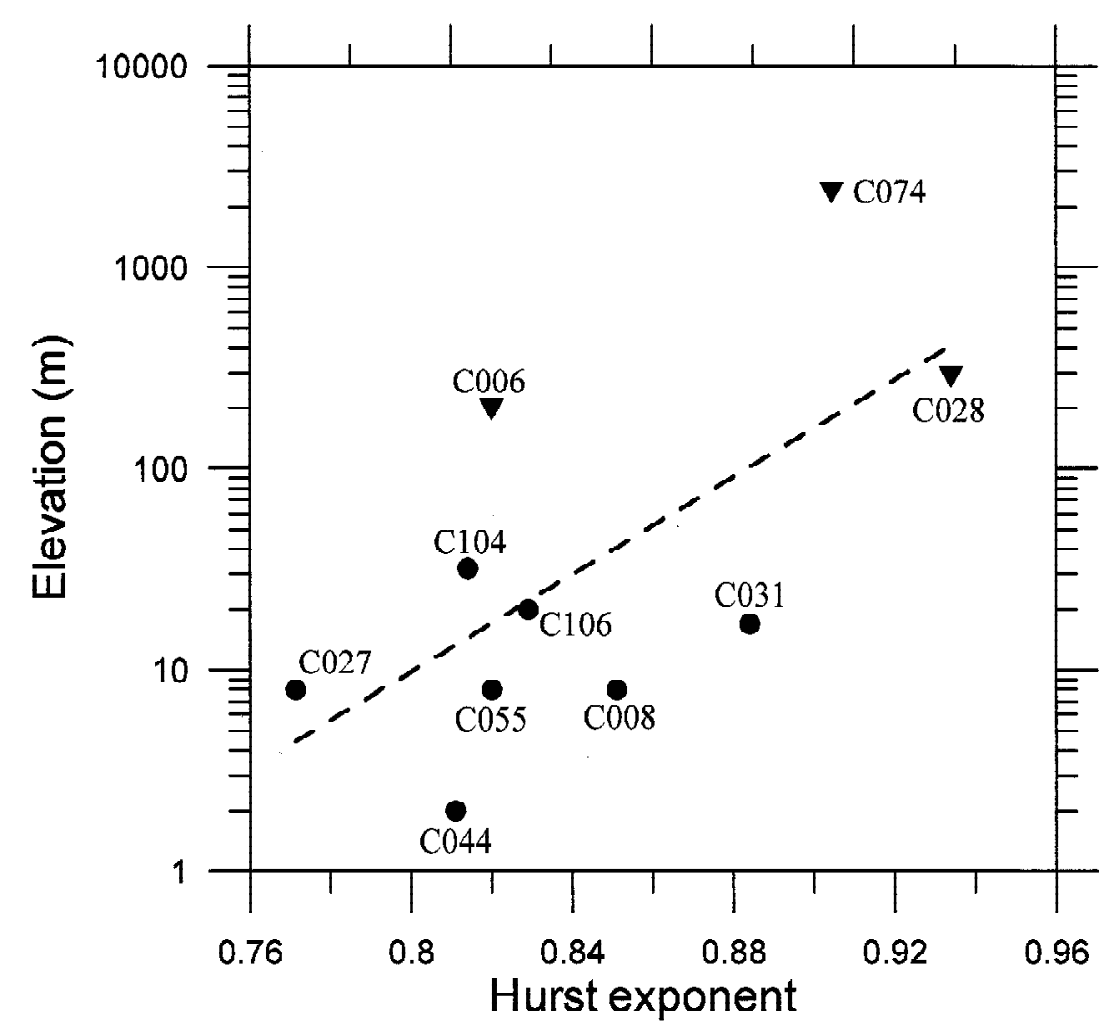

Fig. 4. Distribution of the Hurst exponents $(H)$ of the microtremors along with the elevations of the stations. The black dots are the stations located on the Western alluvial plain, and the black triangles are the stations located in the Western foothills. The dashed line is the regression of their relationship with an exponential law. 
foothills near the mountain and at the rock sites is greater than that on the alluvial plain, near the coast and at the soil sites. Feder (1988) proposed a 'memory effect' to explain the persistence and anti-persistence of a time series. In accordance with Feder's findings, the foothills, the mountain and the rock sites have a stronger 'memory effect' for microtremors than do the alluvial plain, the coast and the soil sites. This is because low frequency microtremors are generally produced and more easily preserved in the foothills, the mountain and the rock sites than at the other three types of sites.

\section{CONCLUSIONS}

Because microtremors are visually random, we used Hurst's rescaled range method to analyze the long-term characteristics of the microtremors recorded at 10 stations in the YunChia area, Taiwan. The $H$ values of the microtremors recorded in this area range from 0.733 to 0.934 , and the average $H$ value is 0.84 . This implies that the microtremors are not independent random signals but are, instead, persistent. Based on our measurements of the microtremors which we performed twice, the microtremors are nonstationary in time, but they are stationary in their long-term characteristics, or in other words, their $H$ values.

The comparatively high $H$ values of the microtremors may be because it is easier for low frequency ground motions than high frequency ground motions to survive. The $H$ values of the microtremors on the alluvial plain, the coast and at the soil sites are lower than those in the foothills, on the mountain and at the rock sites. Therefore, it is concluded that the foothills, the mountain and the rock sites have a stronger 'memory effect' for microtremors than do the alluvial plain, the coast and the soil sites. The results infer that low frequency microtremors are produced and more easily preserved in the foothills, on the mountain and at the rock sites than on the alluvial plain, the coast and at the soil sites.

Acknowledgments We would like to thank two anonymous reviewers for their constructive and thoughtful comments.

\section{REFERENCES}

Feder, J., 1988: Fractals. Plenum Press, New York.

Hurst, H. E., 1951: Long-term storage capacity of reservoirs. Trams. Am. Soc. Civil Eng., 116, 770-808.

Kagami, H., C. M. Duke, G. C. Liang, and Y. Ohta, 1982: Observation of 1 to 5 second microtremors and their application to earthquake engineering. Part II: Evaluation of site effect upon seismic wave amplification due to extremely deep soil deposits. Bull. Seism. Soc. Am., 72, 987-998.

Karner, O., 2001: Comment on Hurst exponent. Geophys. Res. Lett., 28, 3825-3826.

Komm, R. W., 1995: Hurst analysis of Mt. Wilson rotation measurements. Solar Phys., 156, 17-28. 
Lermo, J., and F. J. Chavez-Garcia, 1994: Are microtremors useful in site response evaluation? Bull. Seism. Soc. Am., 84, 1350-1364.

Lomnitz, C., 1994: Fundamentals of earthquake prediction. John Wiley \& Sons, New York, 165-171.

Macchiato, M., 2001: A new approach to investigate the correlation between geoelectrical time fluctuations and earthquakes in a seismic area of southern Italy. Geophys. Res. Lett., 28, 4375-4378.

Mandelbrot, B. B., 1983: The fractal geometry of nature, W. H. Freeman, New York, 247255.

Mandelbrot, B. B., and J. R.Wallis, 1969a: Some long-run properties of geophysical records. Water Resour. Res., 5, 321-340.

Mandelbrot, B. B., and J. R. Wallis, 1969b: Robustness of the rescaled range $R / S$ in the measurement of noncyclic long run statistical dependence. Water Resour. Res., 5, 967988.

Ohta, Y., H. Kagami, N. Goto, and K. Kudo, 1978: Observation of 1 to 5 second microtremors and their application to earthquake engineering. Part I: comparison with long-period accelerations at the Tokachi-Oki earthquake of 1968. Bull. Seism. Soc. Am., 68, 767779 .

Okada, H., 2003: The microtremor survey method. Translated by Suto, K.. SEG, Tulsa, OK, 9-14.

Seht, M. I., and J. Wohlenberg, 1999: Microtremor measurements used to map thickness of soft sediments. Bull. Seism. Soc. Am., 89, 250-259.

Urquizu, M., and A. M. Correig, 1998: Analysis of seismic dynamical systems.J. Seism., 2, $159-171$. 